\title{
ADVANCED COMPUTATIONAL AIDED DEVELOPMENT OF AUTONOMOUS INFLOW CONTROL DEVICE (AICD)
}

\author{
WEIQI YIN 1 , GEORGINA CORONA ${ }^{2}$, AND SHENGJUN YIN ${ }^{3}$ \\ ${ }^{1}$ Halliburton \\ 2601 E Beltline Rd., Carrollton, TX 75006, USA \\ Weiqi.Yin@halliburton.com,www.halliburton.com \\ ${ }^{2}$ Halliburton \\ 2601 E Beltline Rd., Carrollton, TX 75006, USA \\ Gina.Corona@halliburton.com,www.halliburton.com \\ ${ }^{3}$ Halliburton \\ 2601 E Beltline Rd., Carrollton, TX 75006, USA \\ Shengjun.Yin@halliburton.com,www.halliburton.com
}

Key words: Autonomous, AICD, ICD, FEA, Mounting, Carbide, Inflow Control Device, Contact Problems.

\begin{abstract}
Autonomous inflow control devices (AICDs) represent a successful technology utilized in maximizing reservoir sweep and increased oil recovery. They are an evolutionary enhancement over the passive inflow control device (ICD) such as a nozzle or helix type, which have a choke that is fixed for the lifetime of the well. This paper discusses a technique which accelerated the AICD development from defining the operational parameters to delivering a fully functional product, while considering the various mechanical and hydraulic loads that are critical in providing robustness during operations.

Due to limited space availability between the AICD sub-assembly, basepipe dimensions, and complex loading conditions, iterative designs were established to meet the operational parameters. Simulations using finite element analysis (FEA) facilitated the development via performance evaluation of each design under various load conditions. The FEA simulation results provided the direction to refine, optimize and finalize the design. Mechanical loads evaluated in the simulations included: tension, torque, bending, and impact shock, while hydraulic loads included: collapse, burst, and injection pressure. On finalizing the design, the simulation results were validated with prototype testing.

The final design met the operational parameters through FEA, that enabled the successful development of the product, saving more than $50 \%$ of a typical development cycle time. The FEA simulations provided stress information of each feature, modelling the anticipated loading during the service life, which contributed to the improved robustness and complex features reliability. Prototype test samples were manufactured based on the final design. A full range of validation tests were conducted to validate the final design of the simulation model and to establish appropriate operational limitations of the AICD assembly when subjected to various loads. A leak test was performed before and after the applicable tests to verify that a leak path
\end{abstract}


had not developed. At the conclusion of every test, each AICD element (manufactured from tungsten carbide) was inspected for damage to verify the device had not failed. The test results proved the final design could achieve or exceed the minimum requirements under various load conditions using the simulation technique that accelerated the development process. This design has been used as the basis for various other sizes, with a similar mounting system, which have been successfully deployed in field applications.

The use of this technique significantly accelerated the development process. It involved several design iterations and FEA simulations to evaluate various designs throughout the development cycle. FEA has been applied as a value adding tool to guide design optimization, which has been verified by testing, to successfully anticipate the loadings as per operational parameters. In addition to the shortened development process, the validation test development cost was significantly minimized, using FEA, and a robust product was delivered. The validation test results aligned with the FEA predictions.

\section{BACKGROUND / PROJECT GOAL}

Fluidic Diode Autonomous Inflow Control Devices are installed as part of a lower completion, fulfilling multiple purposes. The first benefit of these devices is to balance the production fluid for a more evenly drained reservoir. Improving reservoir sweep has shown higher oil recoveries. A more evenly balanced production also contributes to delaying water and gas coning. The initial Inflow Control Devices in the oil and gas industry were designed to balance flow by adding an intentionah-pressure drop when fluid flows through an eiement such as a nozzle, tube, orifi coning, which was succes (pressure differential) devices.
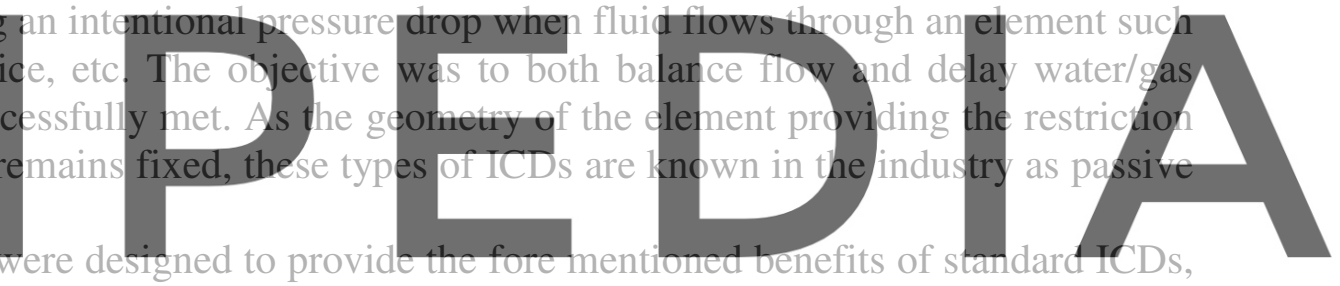

however, providing further additional restriction when water and gas breakthrough occurred.

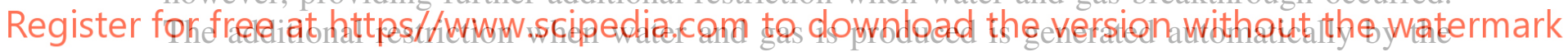
AICDs by detecting the fluid properties of the production fluid. The fluidic diode AICDs possess engineered channels that direct oil through a lower resistance path to the exit hole, creating a low pressure differential similar to a nozzle ICD. Based mainly on viscosity differentiation, the fluidic dynamic channels direct water and gas along a high-pressure drop path to reduce the flow rate of the local AICD in the completion.
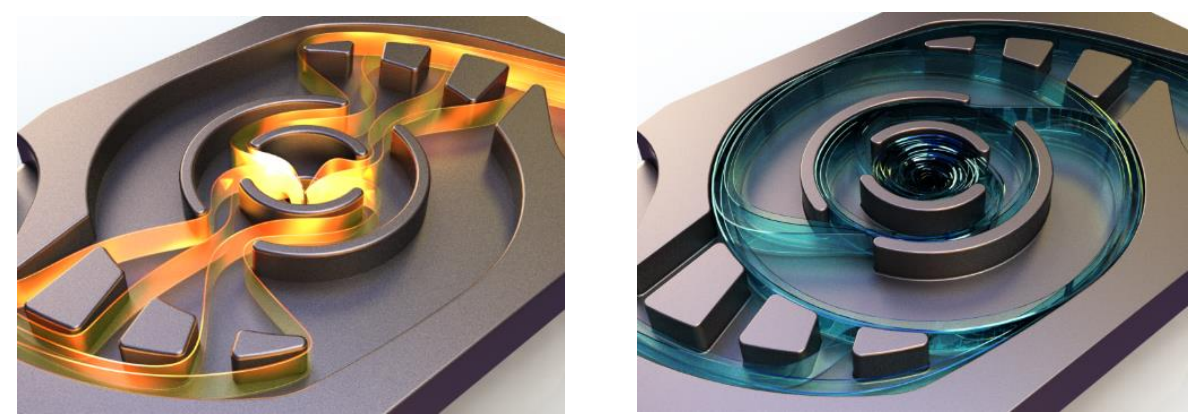

Figure 1: Fluidic Diode AICD. Oil flow path (left), Water/Gas flow path (right) 
The AICDs need to withstand mechanical loads while being transported to the rig site, picked up to the rig floor, being torqued to the completion assembly, and any tension/compression encountered while deploying the completion to Total Depth (TD). The product design should align the ratings and robustness of equipment required to allow operators to successfully complete their wells. Multiple designs and features were considered to ensure the mechanical robustness of the fluidic diode AICD. Though the final validation involves small and full scale testing, optimized FEA modeling can reduce significantly the development time and reduce the amount of physical testing required. Effective computational modeling was successfully applied to develop and design a mounting system for the fluidic diode AICD while minimizing the testing of multiple features and iterations of the equipment.

\section{DESIGN DEVELOPMENT}

Due to limited space between the maximum allowable outer diameter and the base pipe, a new mounting concept was proposed to achieve three goals. First, assemble the AICD carbide to a mounting insert with adequate sealing capability around the AICD post, second, connect the subassembly of the AICD and mounting insert to the base pipe, and third, provide enough protection to the carbide when the entire assembly is subjected to mechanical loading conditions. The design must fit within the limited space and have appropriate strength to withstand different deformation limits without cracking or leaking around the AICD.

The AICD was first mounted into an insert that would eventually be welded on to a base pipe and have a Sand Exclusion screen attached. It was cleternnined that the best way to attach the carbicle to the insert hole conditions without

Each component function. The insert $d$ the rest, thus the overall
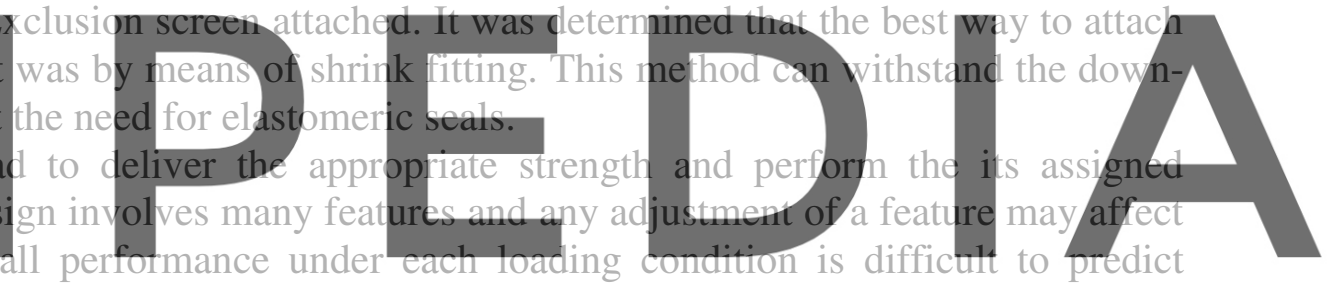
theoretically or through calculation. Additionally, the non-linear contact between the insert and

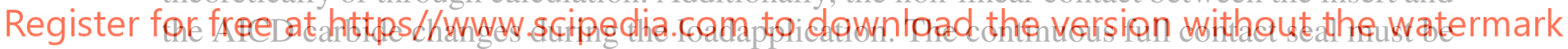
maintained for each required loading scenario.

Various insert designs were studied during the development. FEA was used from the initial design to the final design to verify each loading scenario. The internal design details are not shown to protect proprietary information.

\section{FEA MODELING}

A new mounting system was designed to accommodate the AICD onto the base pipe. Simulations using finite element analysis (FEA) were conducted to facilitate the "development via performance" evaluation of each design under various load conditions. FEA allowed rapid evaluation and development of the AICD mounting system, which effectively leveraged the engineering simulation and design iterations, producing a final design that passed the required qualification test.

Figure 2 illustrates the assembly of the AICD mounted on the base pipe. There is limited space between the base pipe outer diameter and maximum allowable inner diameter of the cover sleeve while subjected to complex loading conditions in downhole conditions. The complex 
design required several design change iterations to meet the requirements of all loading conditions in the downhole environment. The AICD can be subjected to various hydraulic and mechanical loads. Hydraulic loads include collapse and injection pressure tests. Mechanical loads include tension, torque, and shock tests.

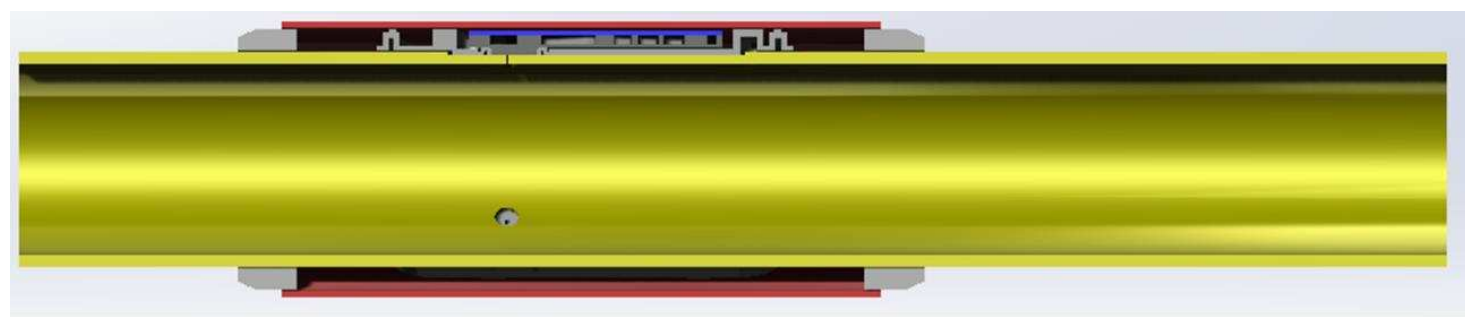

Figure 2. Autonomous Inflow Control Device Mounted on Base Pipe

The performance of the initial design for the AICD system was evaluated when subjected to hydraulic loads including collapse pressure and injection pressure tests. The finite element analysis was conducted using ABAQUS Version 6.14 software [1]. FEA was conducted to check the interference fit between the housing and carbide, and the performance of the assembly when subjected to injection pressure. The injection pressure load is applied to the inner surfaces of the AICD system, as depicted in Figure 3.
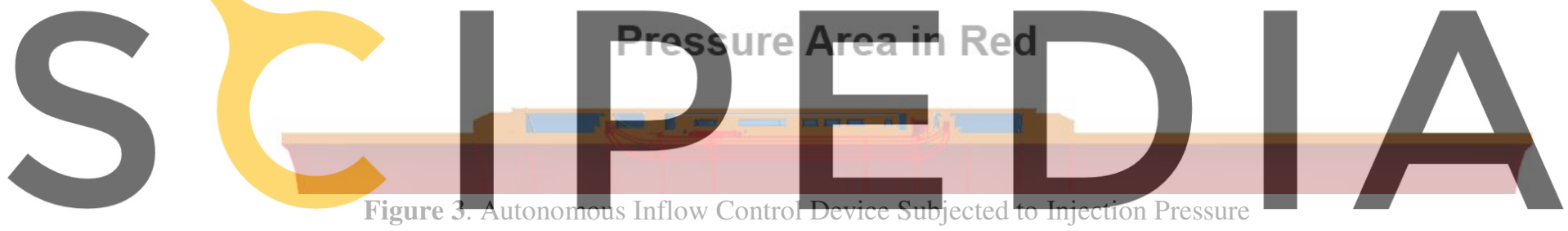

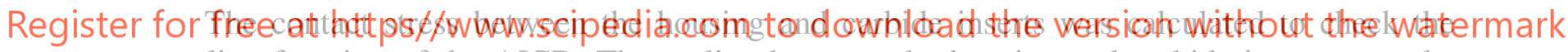
sealing function of the AICD. The sealing between the housing and carbide inserts must be maintained when subjected to the target injection pressure. Design changes were iterated until satisfactory performance was achieved. The structure integrity of the carbide inserts was also evaluated to ensure the carbide would not break under various loading conditions.

The performance rating for the AICD system was evaluated under various mechanical load scenarios in downhole conditions. In the past, designers in the oil/gas industry typically used mechanical load (pressure, tension/compression, torque, etc.) that led to initial yield as the rating criteria, which was very conservative especially when there is typically high stress in the corners due to stress concentration. In this analysis, the concept of the onset of nonlinearity for the tool rating [2] was used. This rating criterion may be used when a tool is subjected to a small number of cycles in cyclic loading conditions. The typical cycle count should be fewer than 200. In this case, small yielding in a local area is usually allowed because fatigue failure is not a concern. The onset of nonlinearity is defined as the load that causes the deformation curve for a tool to become nonlinear, i.e. the global response of the system deviates from linearity. The tension load versus axial displacement curve for one of the designs is illustrated in Figure 4. The sealing capability and the structural integrity of the carbide inserts were also 
checked. If the sealing capability is lost at the onset of nonlinearity, then the lower rating was chosen as the tool rating.

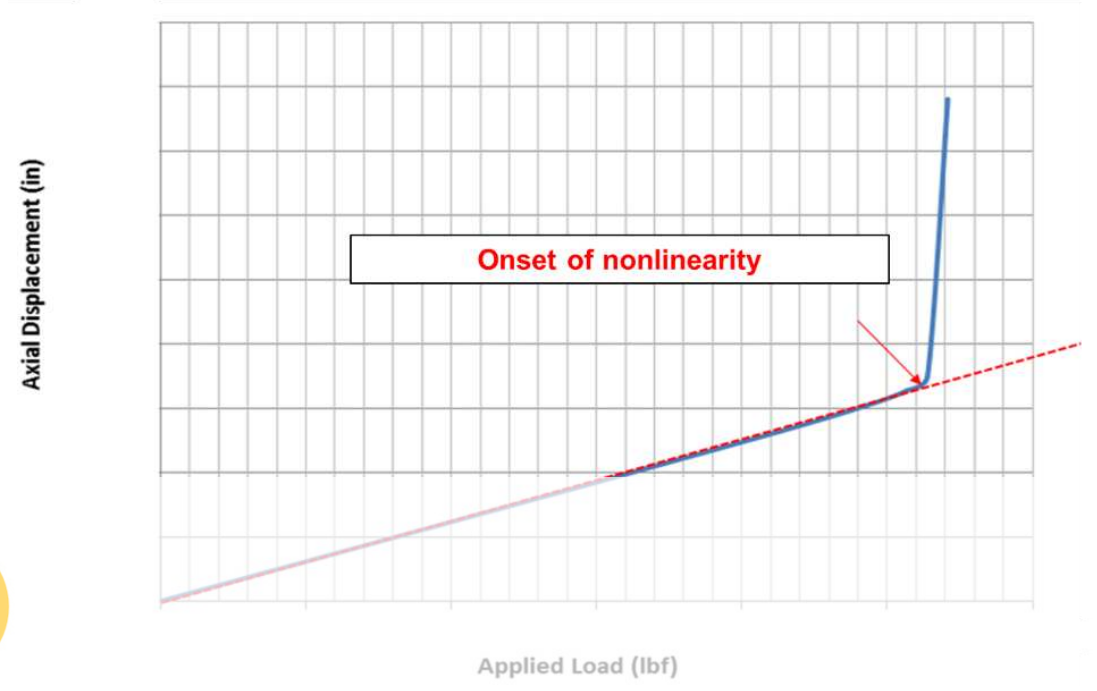

Figure 4. Tension vs. Axial Displacement Curve

Another challenge for the AICD is the potential of shock loading which may occur during transportation and poss simulate a drop test simulation. To maintain th drop height of no greate
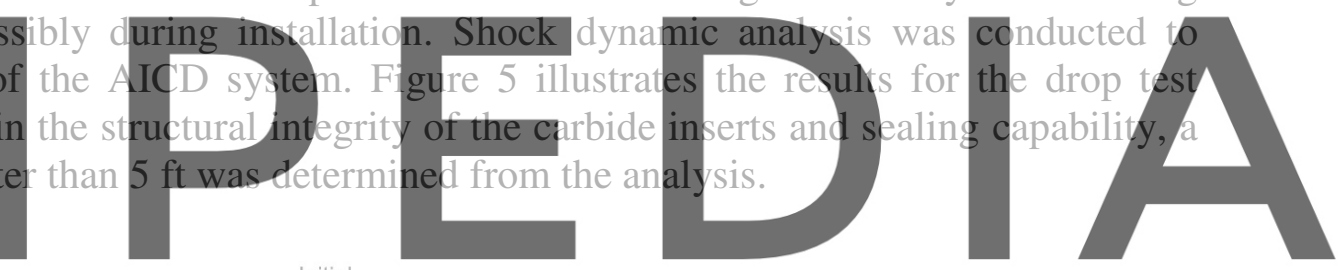

Initial

Register for free at https//www.scipedia.com to download the version without the watermark

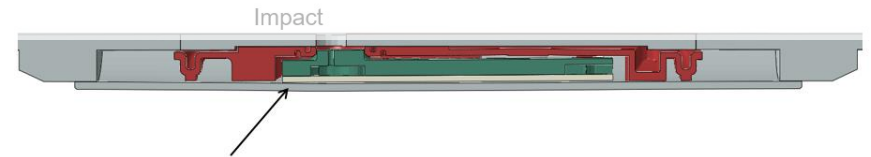

Bounce

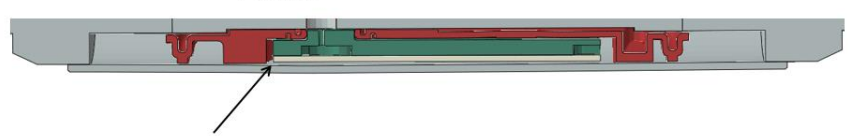

Figure 5. Shock Dynamic Analysis to Simulate the Drop Test of the AICD System.

\section{TESTING AND RESULTS}

Prototype test samples were manufactured and several were tested to determine the maximum load limit that can be applied without damaging the AICD assembly to the point where there is a loss of functionality from what was designed and verified during FEA modelling. Tests performed included:

- Tension test 
- Torque test

- Bend test

- Burst pressure test

- Collapse pressure test

- Injection pressure test

- Shock test

As an example, Figure 6 shows the test set up for the tensile test. A Linear Variable Differential Transformer (LVDT) transducer was fixed onto the two end rings to monitor the displacement near the insert. During the test, two AICD test samples were tested and both had the shroud removed (to eliminate the additional strength from the shroud). The tensile load was increased to the desired load, held, and then released. Each load step was followed by a full visual inspection of the carbide assembly. After each step, no cracks or defects were observed and the carbide remained secure in the assembly. After the initial sample test, a full leak test was performed on the AICD insert, carbide, and shrink fit interface. No leaks were observed, thereby, a second tensile test was conducted with a higher loading. Again, the assembly was fully inspected and leak tested with air, with no damage, leaks, or unsecured components, being observed. Both samples passed the tensile test. The results of the first sample test can be seen in Figure 7.
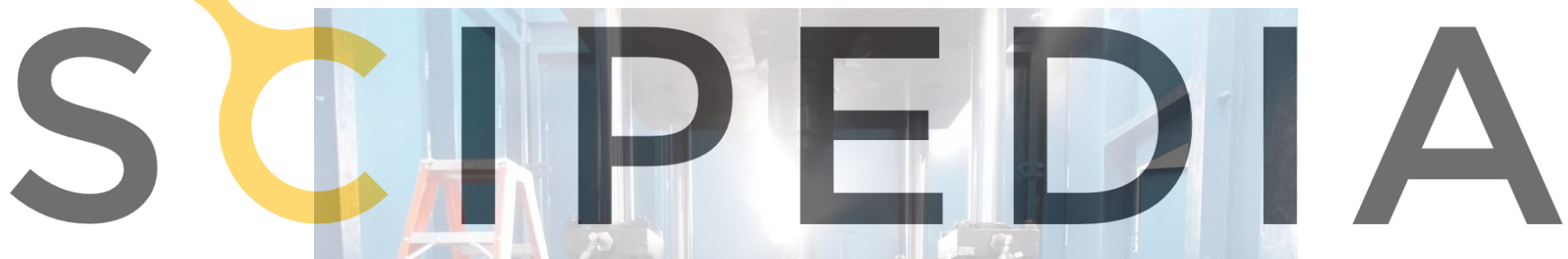

Register for free at https//www.scipedia.com to download the version without the watermark

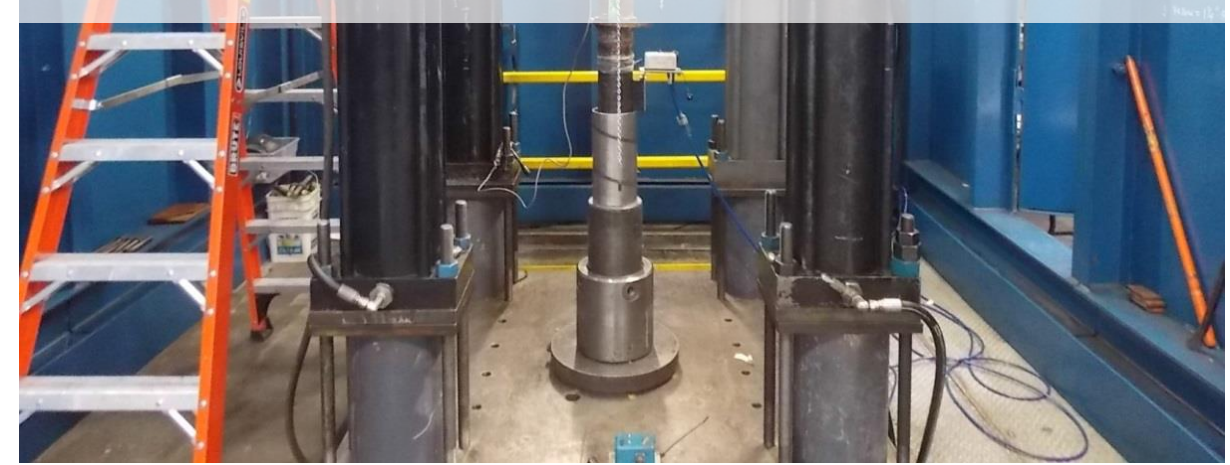

Figure 6: Tensile test sample setup in the vertical test frame with transducers 

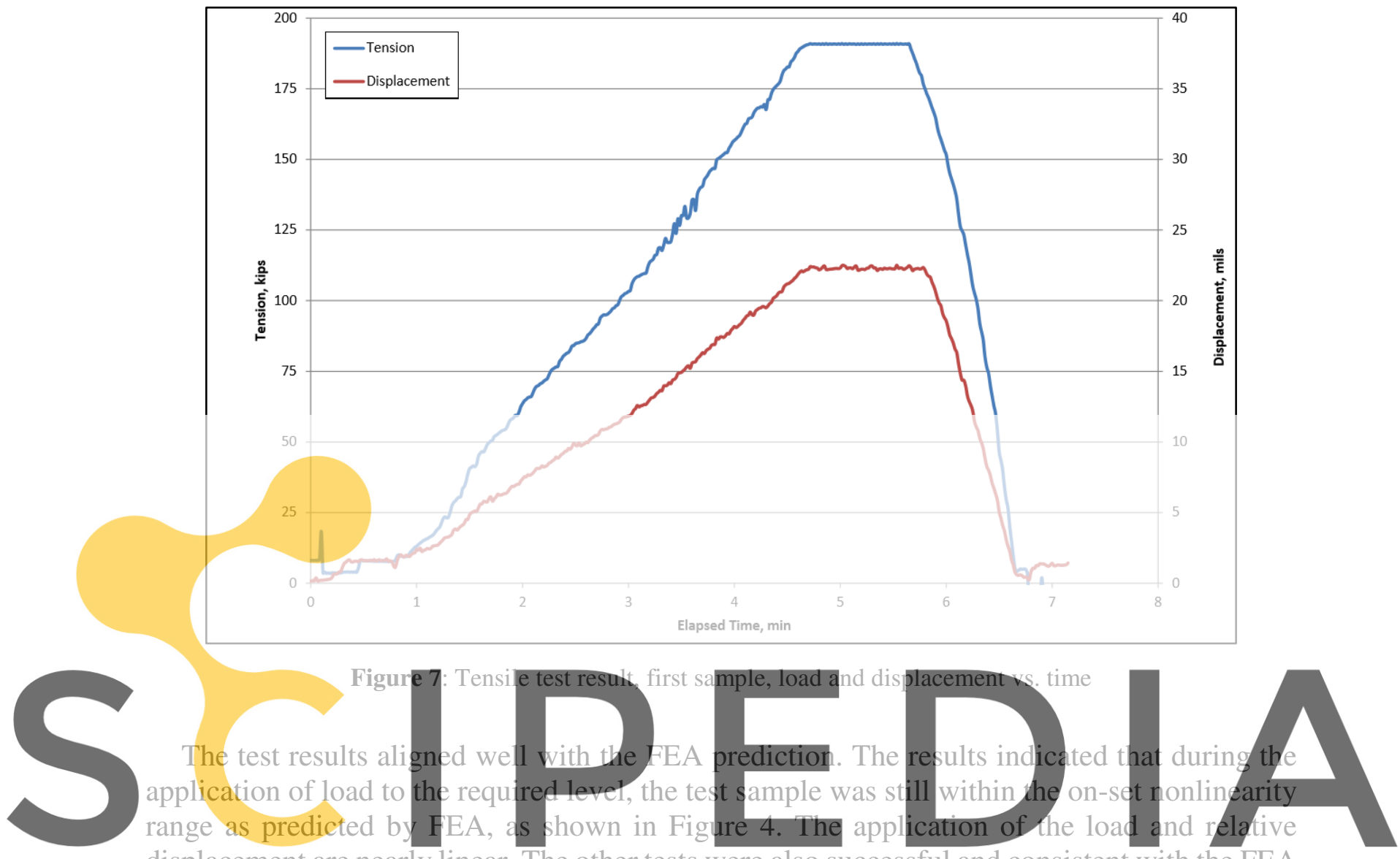

displacement are nearly linear. The other tests were also successful and consistent with the FEA

Register forrefictions. https//www.scipedia.com to download the version without the watermark

\section{FIELD APPLICATIONS}

The FEA simulations provided an insight in to how and where to refine, optimize and finalize the design, with empirical testing proving the predictions from modeling. AICD completions are typically deployed in long horizontal wells, some of which exceeding 10,000 ft MD. The AICD design and its capabilities must allow the completion to be deployed to the desired depth as well as operationally facilitating the pressures, hydraulic loads (burst, collapse, injection) and mechanical loads (tension, compression, torque, bending) required during the life of the well. Validating injection through the AICD using FEA and testing provided operators the flexibility to perform future interventions to inject reservoir treatment fluids for acid stimulations or matrix acidizing.

The mounting system designed has successfully been deployed in multiple land and offshore wells globally proving the robustness and reliability of the design.

\section{CONCLUSION}

The design iterations through FEA simulation significantly accelerated the development 
process and evaluated all designs during the development cycle. FEA has been utilized as a valuable tool in advancing design optimization, which has been validated with physical testing to successfully anticipate the loading conditions per the operational requirements and parameters. In addition to the development process being reduced, the validation test cost was minimized with the use of FEA, and a robust product was delivered. The physical validation test results aligned with the FEA predictions.

\section{ACKNOWLEDGEMENT}

The authors wish to thank the management of Halliburton for the permission and encouragement to present the information in this paper. A special note of thanks is extended to Michael Fripp, John Gano, Jean Marc Lopez, Ryan Novelen and Stephen Greci for their contribution in the development of the AICD product line.

\section{REFERENCE}

[1] Simulia, Abaqus User's Manuel, (2014).

[2] Zhong, A. 2007. Thread Connection Response to Critical Pressures. Presented at the 2007 ABAQUS Users' Conference, Paris, France, 22-24 May.

\section{NOMENCLATURE}
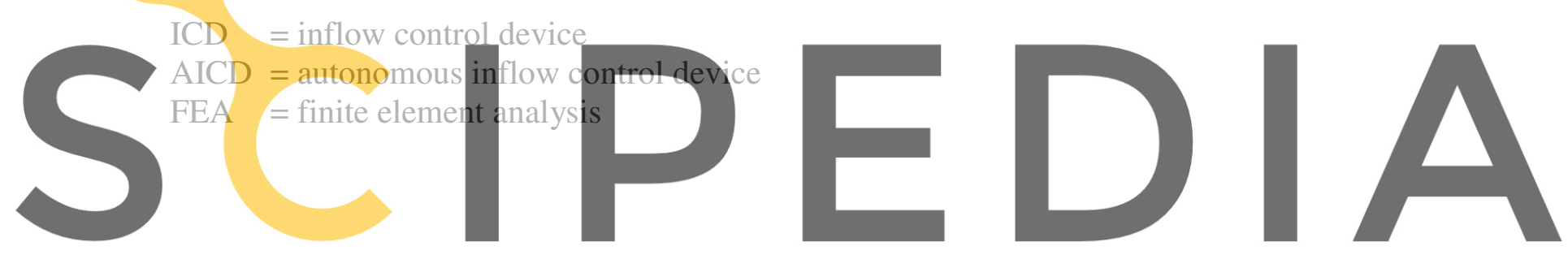

Register for free at https//www.scipedia.com to download the version without the watermark 